\title{
Extraction and Characterization of Polyhydroxybutyrates (PHB) from Bacillus thuringiensis KSADL127 Isolated from Mangrove Environments of Saudi Arabia
}

\author{
Abdullah A. Alarfaj", Mohammed Arshad, Essam N. Sholkamy and Murugan A \\ Munusamy \\ Department of Botany and Microbiology; College of Science, King Saud University - Saudi Arabia
}

\begin{abstract}
Polyhydroxybutyrate $(\mathrm{PHB})$ is a renowned biodegradable plastic that do not release any toxins or residues in the environment like petroleum based plastics. In the present study, 50 bacteria isolated from mangrove niche, Saudi Arabia, were screened for maximum PHB production. All the 50 strains showed positive for PHB production, of which one strain showed maximum of $137 \mathrm{mgL}^{-1}$. The most PHB accumulated bacterium was selected and identified as Bacillus thuringiensis KSADL127, based on phenotypic characterization and 16S rRNA sequence analysis. Characterization of extracted PHB was carried out by FT-IR, NMR, UV spectroscopy, DSC, TGA, and LC-MS, which later confirmed the presence of intracellular accumulated polymer and substantiated as $P H B$.
\end{abstract}

Key words: Mangrove environments, Bacillus thuringiensis, Polyhydroxybutyrate (PHB)

\section{INTRODUCTION}

Plastics are synthetic polymers that are made up of long chains of repeating molecular units called monomers. Monomers are the building blocks of polymers. Monomers such as vinyl chloride, styrene, and acrylonitrile are produced by the petrochemical industry through crude oil distillation at refineries. Plastics are extremely diverse in terms of chemical composition, properties and possible applications, widely distributed in the society and the environment. The petroleum based plastics are indispensable to our daily life. The usage of plastics cannot be eradicated right away, but management of plastic waste product should be done to avoid detrimental effects to humans.

The best way for decomposing plastics is microbial degradation or biodegradation.
Microbial degradation of plastics is caused by enzymatic activities that lead to a chain cleavage of the polymer into monomers. Microorganisms utilize polythene film as a sole source of carbon resulting in partial degradation of plastics. Many solid waste management programs have been conducted by various countries to reduce plastic waste and have come up with new ways to produce biodegradable plastic materials such as Polyhydroxybutyrates (PHBs). These are the natural biopolymers, that are synthesized and catabolized by microorganisms particularly bacteria (Witholt and Kessler 2002; Akar et al. 2006; Berlanga et al. 2006). There are more than 300 of such species known to produce PHB's (Berlanga et al. 2006). A number of bacteria such as Azotobacter, Bacillus, Archaebacteria, Methylobacteria and Pseudomonas have been found to accumulate PHB to varying levels. Ralstoniaeutropha (formerly Alcaligenes

*Author for correspondence: aalarfajj@ksu.edu.sa 
eutrophus) was found to accumulate PHBs up to 80 per cent dry weight (Lee 1996). Macrae and Wilkinson (Macrae and Wilkinson 1958) first reported that Properties of biodegradability of PHB produced by B. cereus and B. megaterium. Shape, size, structure, physical properties of these granules differ from organism to organism accordingly (Ha and Cho 2002). Beijerinck was the first to observe lucent granules of PHB in bacterial cells in 1888 (Chowdhury 1963). Hence the previous studies showed that Bacillus cereus, Bacillus subtillis, B. megaterium have been shown to produce higher amounts of PHB using agro-industrial waste with variable level of carbon sources (Ghate et al. 2011). Besides recent studies revealed that the highest production of PHB using Bacillus thuringiensis along with $\mathrm{H}_{2}$ gas (Singh et al. 2013), glucose: $\mathrm{NaNO}_{3}$ in 4:1 ratio and with the help of UV which gave sharp peak at $235 \mathrm{~nm}$ characterized by crotonic acid indicating presence of PHB (Pal et al. 2009).

The aim of this present study is to screen the biopolymer PHB producing Bacillus sp. from the mangrove environments located on the sea coast of the Arabian Gulf located near Dammam. The isolated bacterial cells were identified and characterized by morphological, biochemical, physiological and molecular characteristics. Then the new strain was identified as Bacillus thuringiensisKSADL127. The PHB was extracted and purified after mass culture of the selected bacterial strain. The purified PHB was then identified and characterized employing many analytical methods such as Nuclear Magnetic Resonance (NMR) Spectroscopy, Fourier Transform Infrared Spectroscopy (FTIR) Differential scanning calorimetry (DSC), Thermo gravimetric Analysis and Liquid Chromatography Mass spectrometer and Ultraviolet-visible spectroscopy.

\section{MATERIAL AND METHODS}

\section{Isolation of bacterial cells}

The PHB accumulated bacterial cells were isolated from mangrove environment according to Hirad et al. 2013 procedure (Hirad et al. 2013). 45 sea coast samples were collected from the mangrove area of Tarot Island, Qatif and Dammam on the Arabian Gulf coast in different places at intervals of 200 meters at each site and all the collected samples were frozen and transported to laboratory. The samples were pour plated on ZoBells marine agar medium and plates were incubated at $28^{\circ} \mathrm{C}$ for 510 days. After incubation the isolated colonies were purified and stocked with $40 \%$ glycerol mixed cell culture and stored at $-80^{\circ} \mathrm{C}$ for further study.

\section{Subculture and purification of isolates}

All the isolates from glycerol stocked bacterial cultures were subjected to further subculture on Zobells marine agar medium and purified by repeated streaking on the same medium. After purification the pure cultures were maintained as agar slope cultures at $4{ }^{\circ} \mathrm{C}$.

\section{Preliminary Screening for potential PHB producing Bacterial Strain}

Preliminary screening of PHB producing bacteria was done using fluorescence plate assay using complex nitrogen limiting agar medium (Sun et al. 1994). A solution was used in the medium to make it to final concentration of about $0.5 \mu \mathrm{g} / \mathrm{mL}$. Test cultures which were previously grown on Zobells agar slants $(16 \mathrm{~h}$.) were patched on Nile blue agar plates and incubated at $37^{\circ} \mathrm{C}$ for $5-7$ days. The single cell colonies that grew well on the surface of the agar were then examined for fluorescence under UV light for detection of PHB accumulation. Those strains that showed strong fluorescence were selected as potential PHB producers.

\section{Media Preparation}

A 2 liters conical flask containing one liter of deionized water, dissolved the following contents by mixing and autoclaved at $121^{\circ} \mathrm{C}$. Glycerol and $\mathrm{MgSO}_{4} \cdot 7 \mathrm{H}_{2} \mathrm{O}$ were autoclaved separately and added to the autoclaved medium after cooling down to $60^{\circ} \mathrm{C}$. Contents were mixed well to dissolve the added substances and used later. For preliminary screening of the PHB producing bacterial strains Nile blue solution was added to the medium such that the final concentration of the same was $0.5 \mu \mathrm{g} / \mathrm{mL}$. To prepare solid agar medium in plates $2 \%(\mathrm{w} / \mathrm{v})$ agar was added to the medium.

\section{Secondary Screening for PHB accumulation by Fluorescence Microscopy}

Isolates that showed potential for PHB production were selected and subjected to further secondary screening for confirmation with the help of fluorescence microscopy (Olympus BX 41) (Ostleand Holt 1982). A loopful of bacterial cell 
culture $(48 \mathrm{~h})$ from the Zobells medium was heat fixed on a clean glass slide. Nile blue A stain (1\%) was added and kept for $60 \mathrm{~s}$. Then $8 \%$ aqueous acetic acid was added to the smear and rinsed in order to remove excess stain. The smear was then air dried and observed at an excitation wavelength of $460 \mathrm{~nm}$ to detect presence of PHB granules within cells.

\section{Selection of potential bacterial strain and Identification}

The bacterial isolate that exhibited accumulation of PHB within cells were selected. The selected isolate was then identified based on polyphasic taxonomy, which included morphological, biochemical, physiological and molecular characteristics. Molecular ribotyping was done based on the gene sequence of 16s RNA by SciGenom Labs Pvt. Ltd, Cochin, Kerala, India.

\section{Extraction of PHB from bacterial cells}

The PHB produced by the bacterial cells were extracted by mass culturing the selected bacterial strain Fresh culture $(16 \mathrm{~h})$ of the selected potential bacterial isolate was inoculated (3-5\% inoculum) in 1 liter of Complex Nitrogen Limiting Medium containing in the flask and incubated at $37^{\circ} \mathrm{C}$ for 96 $\mathrm{h}$ in a rotary shaker. After growth the biomass obtained in the culture flask was subjected to PHB extraction using boiling chloroform as solvent since it is considered to be efficient for extracting polymer (Findlay and White 1983).

\section{Characterization of PHB}

The purified PHB was identified and characterized by employing the following analytical methods

\section{Nuclear Magnetic Resonance (NMR) Spectroscopy (JEOL Eclipse $400 \mathrm{MHz}$ ) \\ The spectra were recorded for the extracted PHB sample using deuterated solvent $\mathrm{CDCl} 3$. The instruments used for analysis was JEOL Eclipse $400 \mathrm{MHz}$ NMR spectrometer from Japan. Tetra methyl saline (TMS) was used as external reference. Chemical shifts were reported in ppm and coupling constants were reported in $\mathrm{Hz}$.}

Fourier Transform Infrared Spectroscopy (FTIR) (Perkin Elmer $1750 \quad$ FT-IR spectrometer)

The PHB sample was mixed with Potassium Bromide (KBr) in a sufficient ratio to make transparent pellet and it was grinded in Motor and Pestle using hydraulic pressure instrument.
Prepared pellet was kept in sample holder and IR rays were passed through it at a range of 4000-400 $\mathrm{cm}^{-1}$. Obtained results were analyzed for the determination of functional groups.

\section{Differential scanning calorimetry (DSC) (METTLER TOLEDO DSC 1 Star* System)}

$3 \mathrm{mg}$ of sample was taken in a tin crucible heated at a rate of $10^{\circ} \mathrm{C} / \mathrm{min}$. under nitrogen atmosphere to $400^{\circ} \mathrm{C}$ and by using these parameters the experimental method was implemented and results were obtained using automated system software

\section{Thermo gravimetric Analysis (TGA) (METTLER TOLEDO TGA 1 Star* System)}

$6 \mathrm{mg}$ of sample was taken in Alumina crucible heated at a range of $50^{\circ} \mathrm{C} / \mathrm{min}$ under nitrogen atmosphere to $600^{\circ} \mathrm{C}$ using these experimental conditions the results were obtained and interpreted with the help of automated software.

Liquid Chromatography Mass spectrometer (LC-MS) (Waters Acquity)

Sample was diluted in Chloroform and infused directly into MS detector to obtain the spectra.

Ultraviolet-visible spectroscopy (PerkinElmer Lambda 35 UV/VIS spectrophotometer)

Chloroform was used as standard solution and sample was diluted in chloroform and later absorbance was measured between ranges of 100$800 \mathrm{~nm}$.

\section{RESULTS AND DISCUSSION}

Selection of potential bacteria that produce PHB Out of 150 bacterial isolates that were screened for PHB production, 50 isolates showed positive results after preliminary screening which was based on visualization of the isolates using UV trans illuminator after growth on agar plates incorporated with Nile Blue A as fluorescent Dye. Bacterial isolates that appeared as Dark bluish white colonies under UV were selected as potential PHB producers. Among the 50 isolates which were subjected to secondary screening three isolates were highly potential for PHB production. Appearance of orangish red colonies under Immunofluorescence microscopy confirmed PHB accumulation by bacterial colonies. Among the three strains, bacterial strain KSALD127 produced maximum PHB production as compared to other isolates and 
hence it was selected as the potential strain for further studies.

In spite of the fact that during the past few years, the production of PHB by bacteria and their biosynthesis pathways have been extensively studied, there exists a dearth of information on the prospects of harnessing PHB- producing bacteria from the mangrove environments till date. PHB accumulation by bacterial species was known since long time. However their industrial value is very limited or to some extent because of high cost of the available medium for bacterial growth and supplementation of $\mathrm{C}$ source for PHB accumulation (Reddy et al. 2003).

Marine environments are natural harbors and major habitats for new and novel bacterium which can produce high biomass of PHB. Mangrove environments or the sediments near to mangrove contain accumulated PHB within Vibrios as the studies conducted by Chien et al. 2007. Arun et al. 2009 found that along with Vibrios, Bacillus cereus and mycoides also have an ability to accumulate PHB from mangrove environments of south west Asia (Kerala). Very few studies from Saudi Arabia have shown to produce PHB from sources like soil and water using date palm syrup (Khiyami et al. 2011). Saudi Arabia has a vast saline coastal area near the eastern province which was explored for collecting samples of leaf litter. In this context in our study Bacillus thuringiensis KSBM 127 is highly potential for PHB production and was successfully isolated from the mangrove environment of Saudi Arabia.

\section{Identification of the selected potential bacterial strain KSADL127}

Based on Nucleotide homology and phylogenetic analysis studies, it was concluded that the selected potential bacterial isolate 127 has significant similarity with $B$. thuringiensis. Amplicon obtained after PCR amplification of 16S r RNA gene of the bacterial strain KSADL127. All the results led to the conclusion that the selected bacterial isolate KSALD127 is a strain of B. thuringiensis. The phylogenetic studies on this strain showed $97 \%$ homology with other known species from database available. This indicated that this gram positive, rod shaped bacterium is a native of mangrove environments.

\section{Extraction of PHB}

The isolated culture was employed for mass growth for 4-7 days in a rotary shaker for $37^{\circ} \mathrm{C}$.
After seven days the turbidity appeared in the medium .Then the sample was extracted using Soxhlet apparatus. Crude PHB was obtained as a pellet after extraction in Falcon tubes then it was driedusing oven.

PHB was quantified gravimetrically as given below:

\section{Crude PHB}

Crude PHB extracted from 1Lit of the medium in Falcon tube

Weight of empty Falcon tube $=13.524 \mathrm{gm}$ Weight of crude PHB

$=13.11 \mathrm{gm}$ $=0.414 \mathrm{gm}$

\section{After purification of $\mathrm{PHB}$}

Weight of purified polymer with Round bottom flask (RB) $\quad=116.328 \mathrm{gm}$ Weight of empty Round Bottom flask $\quad=116.191 \mathrm{gm}$ Weight of Purified Polym $\quad=0.137$ gms or $137 \mathrm{mg}$

Some previous research reported that PHB was produced by a large number of gram positive and gram negative bacterial species (Mergaert and Swings 1996; Verlinden et al. 2007). Maximal PHB production $(1.45 \mathrm{~g} / \mathrm{L})$ was reported in $B$. megaterium SW1-2 (Mahmoud et al. 2012) and $280 \mathrm{mg} / \mathrm{L}$ of in Rps.palustris (Ramchander et al. $2010)$. At the same time a poly- $\beta$-hydroxybutyrate (PHB) accumulating, Gram positive $B$. thuringiensis R1 was isolated from the soil samples and reported already (Rohini et al. 2006). Some of the Bacillus species have been reported to accumulate $6-36 \%$ PHB of the cell dry mass (Belma et al. 2000) and B. thuringiensis IAM 12077 was reported as; $0.2 \mathrm{~g} / \mathrm{L}$ to $1.2 \mathrm{~g} / \mathrm{L}$ (Pal et al. 2009).

\section{Characterization of PHB}

The purified PHB was characterized by UVSpectrophotometer analysis, Nuclear Magnetic Resonance (NMR) Spectroscopy, Fourier Transform Infrared Spectroscopy (FTIR), Differential scanning calorimetry (DSC), Thermogravimetric Analysis (TGA), and Liquid Chromatography Mass spectrometer (LC-MS) studies. The results obtained are presented below. After a lot of research on extraction techniques of PHB from B. thuringiensis has being studied for an instance using Sodium hypochlorite ( $\mathrm{Pal}$ et al. 2009) and solvents like propanol.

UV-Spectrophotometer analysis (PerkinElmer Lambda 35 UV/VIS spectrophotometer) 
Absorbance of UV spectra for PHB isolated from Bacillus thuringiensis was measured at $235 \mathrm{~nm}$ using $\mathrm{CHCl}_{3}$ as standard.

\section{NMR spectra analysis (JEOL DELTA NMR 1D Complex)}

Spectral analysis of ${ }^{1} \mathrm{H}$ in Figure 1 revealed doublet proton of $\mathrm{CH} 3$ at peak 1.25 , multiplet peaks ranging from 2.46-2.57 indicating $\mathrm{CH} 2$ proton and triplet at 5.23 as a result of proton splitting. ${ }^{13} \mathrm{C}$ NMR spectra in Figure 2 showed 4 major peaks resembling 4 carbon moieties (a, b, c, d) and CDCL3 peak shown at range 76.77 to $77.41 \mathrm{ppm}$. Expected chemical structures drawn from the conclusive data are presented in the spectra. Spectral analysis of ${ }^{1} \mathrm{H}$ revealed doublet proton of $\mathrm{CH} 3$ at peak 1.25, splitting. 13C NMR spectra showed 4 major peaks resembling 4 carbon moieties and CDCL3 peak shown at range 76.77 to $77.41 \mathrm{ppm}$.

Expected chemical structures drawn from the conclusive data presented in the spectra is

${ }^{1} \mathrm{H}-\mathrm{NMR}\left(\mathrm{CDCl}_{3}, 400 \mathrm{MHz}\right) \delta 1.25(\mathrm{~d}, J=6.60 \mathrm{~Hz}, 3 \mathrm{H}$, $\left.\mathrm{CH}_{3}\right), 2.46-2.57\left(\mathrm{~m}, 2 \mathrm{H}, \mathrm{CH}_{2(2 \& 3)}\right), 5.23(\mathrm{t}, J=6.60$ $\mathrm{Hz}, \quad 1 \mathrm{H}, \quad \mathbf{C H}$ ); (Note: d=doublet, $\mathbf{m}=$ multiplet, $\mathrm{t}=$ triplet, $j=$ Splitting constant $)$.

These findings were co-related with the findings of Arun et al. 2009 for ${ }^{1} \mathrm{H}$ NMR as spectra was not shown and values for $13 \mathrm{C}$ were missing and the assumed structure from the spectra of 13C NMR relates with structure suggested by Redzwan et al.

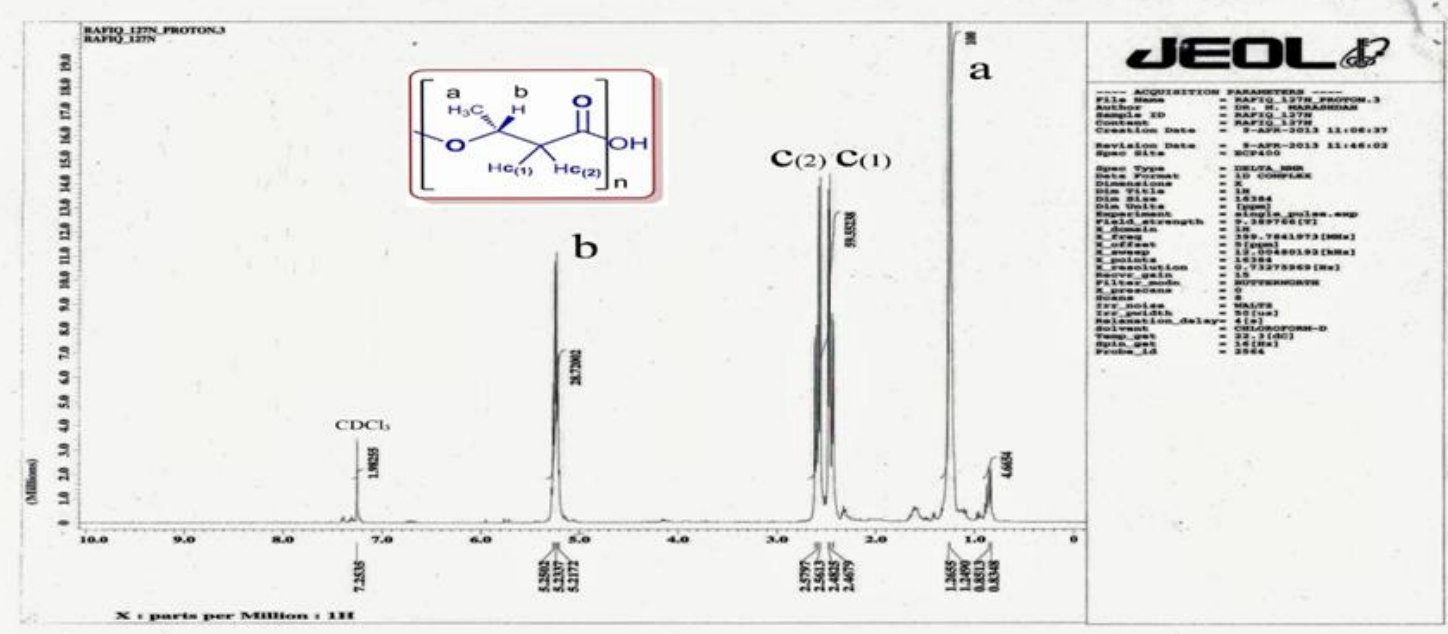

multiplet peaks ranging from 2.46-2.57 indicating $\mathrm{CH} 2$ proton and triplet at 5.23 as a result of proton

1997 and confirming that the isolated compound is PHB.

Figure 1 - ${ }^{1} \mathrm{H}$ NMR Spectra of Polyhydroxybutyrates extracted from Bacillus thuringiensis.

\section{Fourier transforms infrared spectroscopy (FTIR) Spectra Analysis}

Polymer extracted from B. thuringiensis was subjected to FTIR analysis using Perkin Elmer 1750 FT-IR spectrometer (Prestige-21, FTIR8400S, Shimadzu Corporation, Kyoto, Japan (using $\mathrm{NaCl}$ cell) shown in Figure 3. From the spectrum obtained it was inferred that the band at 3435 corresponds to $\mathrm{OH}$ (Hydroxyl) group, whereas band at 1731 represents $\mathrm{C}=\mathrm{O}$ (Carbonyl) and $\mathrm{COO}$ (ester) groups. The band at 1454 corresponds to $\mathrm{CH}$ showing asymmetrical stretching and bending vibration in $\mathrm{CH}_{3}$ group, whereas band at 1379 representing $\mathrm{COH}$ bond.
Stretch of bands ranging from 1057-1277 showed $\mathrm{C}-\mathrm{O}$ bonding. FTIR studies revealed that band at 3435 corresponds to $\mathrm{OH}$ (Hydroxyl) group, whereas band at 1731 represents $\mathrm{C}=\mathrm{O}$ (Carbonyl) and COO (ester) groups. The band at 1454 corresponds to $\mathrm{CH}$ showing asymmetrical stretching and bending vibration in $\mathrm{CH}_{3}$ group, whereas band at 1379 representing $\mathrm{COH}$ bond. Stretch of bands ranging from 1057-1277 showed $\mathrm{C}-\mathrm{O}$ bonding. The analyzed results correlated with the report of Arun et al. 2009 confirming that the isolated compound was PHB. 


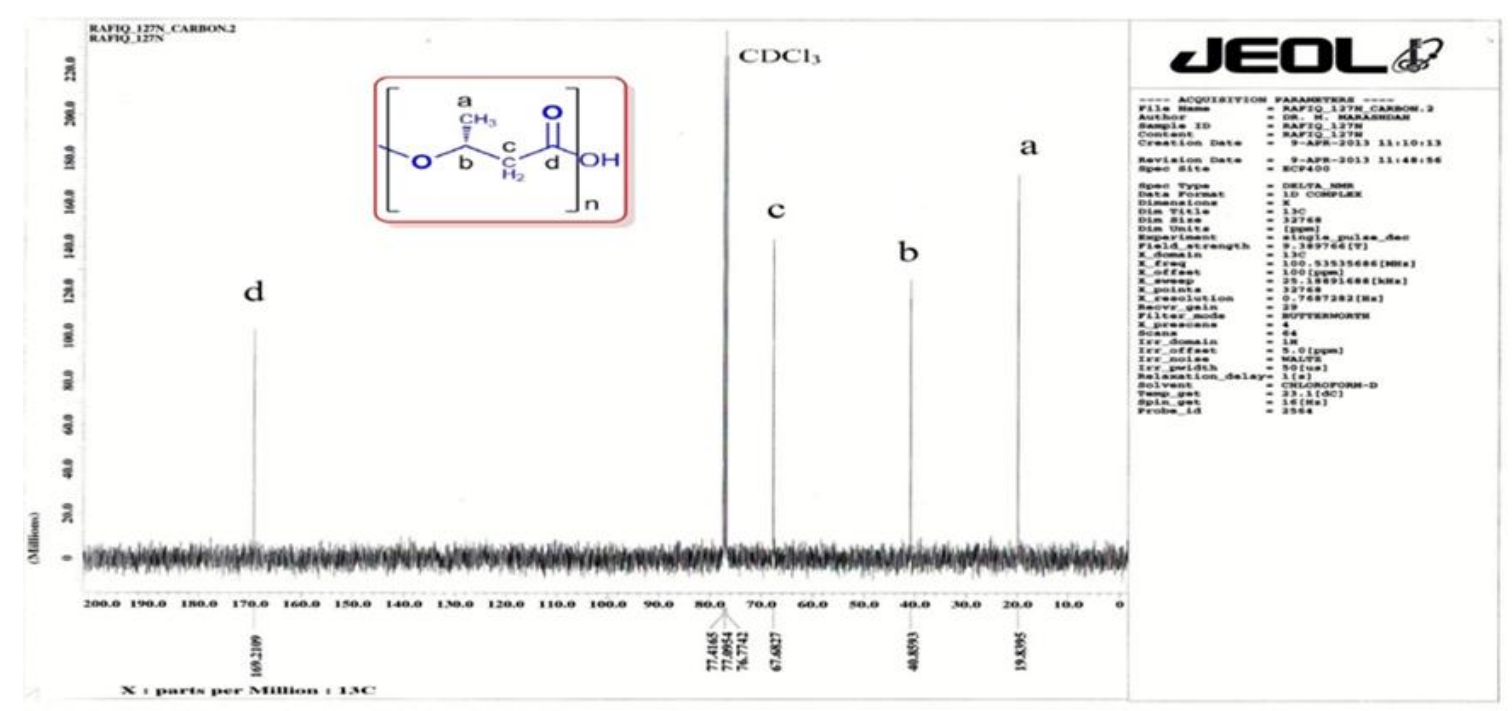

Figure 2 - ${ }^{13} \mathrm{C}$ NMR Spectra of Polyhydroxybutyrates extracted from Bacillus thuringiensis.

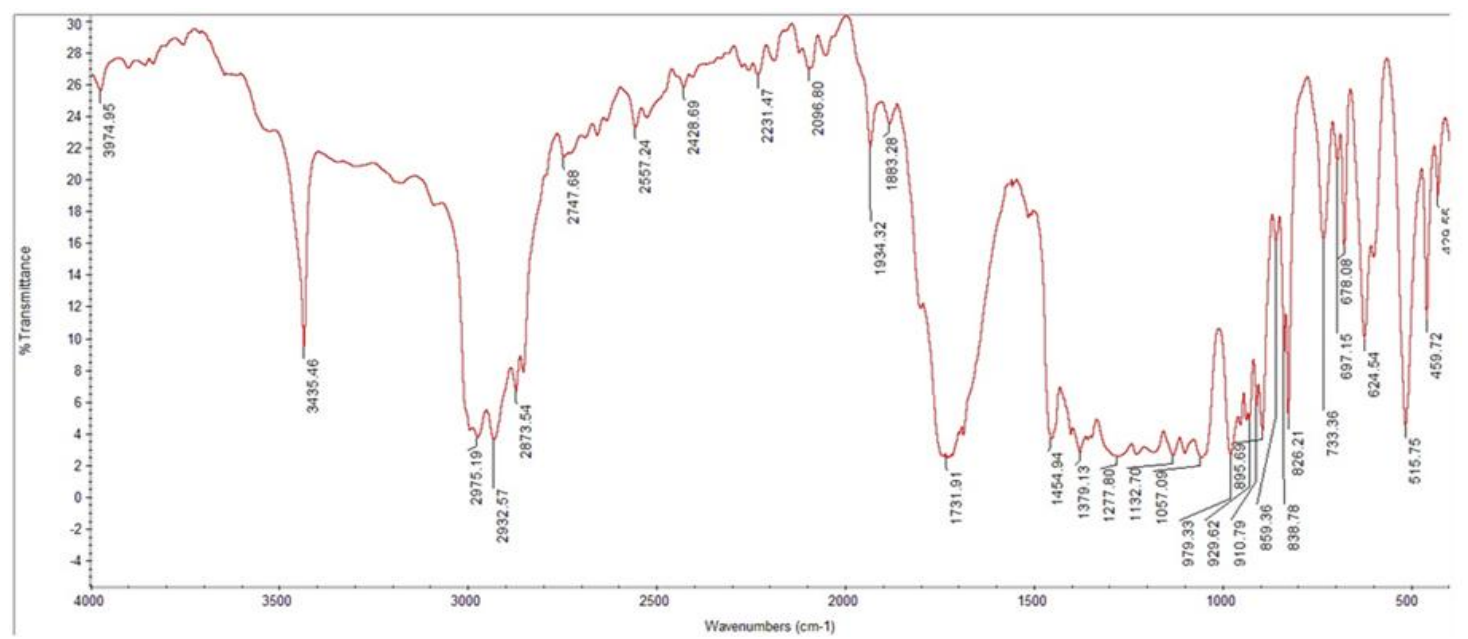

Figure 3 - Fourier transform infrared spectroscopy (FTIR) spectral analysis of biopolymer from B. thuringiensis.

\section{Thermal Analysis}

Thermal analysis was done by Differential scanning calorimetry or DSC (METTLER TOLEDO DSC 1 Star* System). The results obtained for the thermal analysis presented in Figure 4 indicated that the melting point of this PHB polymer was $283+1^{\circ} \mathrm{C}$. On an increasing temperature ranging from $50^{\circ} \mathrm{C}$ to $450^{\circ} \mathrm{C}$.

Thermo gravimetric analysis or TGA (METTLER TOLEDO TGA 1 Star* System)

Thermal degradation of polymer was carried out by increasing the temp by $50^{\circ} \mathrm{C}$ per unit. It was found that weight loss of the sample was approx. $290 \pm 10^{\circ} \mathrm{C}$ that the PHB can withstand around $300^{\circ} \mathrm{C}$ without undergoing any physical or chemical change.

\section{Liquid Chromatography-Mass Spectrometry Analysis (LC-MS)}

Instrument used: Waters Manchester, UK ACQUITY UPLC system Spectra was analyzed and conclusion was brought from it is described below. Molecular Mass of the Polymer was 104.5 and Molecular weight of Monomer unit was 86 . According to Mass Calculations 3 repetitive monomers units are attached to basic monomer unit.

$104.5+86.0 \times 3=104.5+258=362.5$ 
Molecular mass of the polymer was found to be 362.5 , due to negative ionization phenomenon of Mass spectra Deprotonation that takes place thereby reducing one proton leaving the value as 361.5 which can be seen from the spectra giving the confirmation of the compound (Fig. 5).

Molecular mass of the polymer was calculated using repetitive units. Each repeating unit corresponding to molecular weight of $86.0 \mathrm{KD}$. Finally the peak at 361.5 correlated with the value observed after deprotonation are approx. the same hence confirming the polymer to be having 4 basic monomers linked in a chain when injected in spectrometer and read by detector using LCMS studies. No literature is found related to studies by LCMS and it has a significant impact on my results confirming the polymer as such.

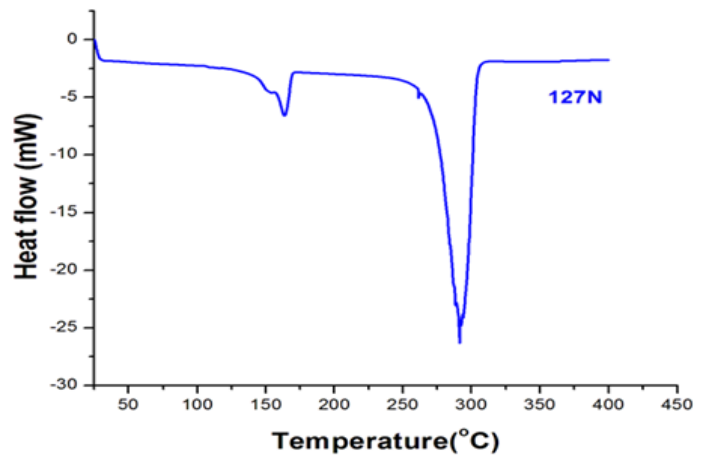

Figure 4 - Differential scanning calorimetry (DSC) analysis obtained for Biopolymer PHB.

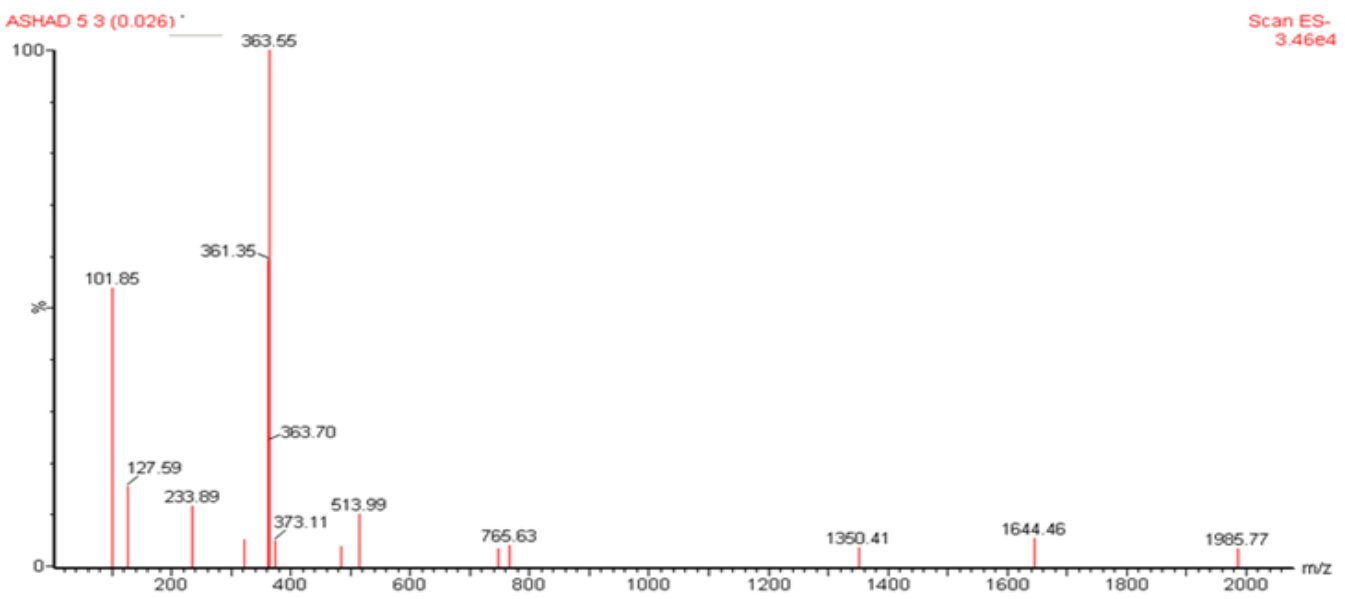

Figure 5 - LC-MS spectra of Polyhydroxybutyrate diluted in Chloroform.

\section{CONCLUSION}

The results of the present study provide environmentally and economically important potential strain $B$. thuringiensis strain KSBM 127 from the mangroves environment of Gulf region for the production of biodegradable plastics. Molecular characterization and phylogenetic studies confirmed the sample number 127 as $B$. thuringiensis. The purified PHB was characterized by different analytical techniques. For large scale production of PHB, further study must be needed. Use of inexpensive substrate, optimization of the medium, recombinant microbial strains, more efficient fermentation process and new extraction process devoid of chlorinated carbons are also needed for new eco-freindly techniques. To the best of our knowledge, this is the first work to isolate and identify a new strain $B$. thuringiensis KSADL127 to produce the PHB (137 mg/L) from Tarot Island, Qatif and Dammam on the Arabian Gulf coast region. Hence continuous exploration of untrapped marine fields and new microbes may reveal many new molecular entities with better biodegrading potentials. This sort of research will confront the emergence of eco-friendly environment in near future.

\section{ACKNOWLEDGEMENTS}

This work was supported by King Saud University, Deanship of Scientific Research, College of Sciences Research Centre. 


\section{REFERENCES}

Akar A, Akkaya EU, Yesiladali SK, Celikyilmaz G, Cokqor EU, Tamerler C, et al. Accumulation of polyhydroxyalkanoates by Microlunatus phosphovorus under various growth conditions. J Ind Microbiol Biotechnol. 2006; 33: 215-220.

Arun A, Arthi R, Shanmugabalaji V, Eyini M. Microbial production of poly-beta-hydroxybutyrate by marine microbes isolated from various marine environments. Bioresource Technol. 2009; 100: 2320-2323.

Belma A, Zehra Nur Y, Yavuz B. Determination of PHB growth quantities of certain Bacillus species isolated from soil. Turkish Electronic J Biotechnol. Special issue; 2000; 24-30.

Berlanga M, Montero MT, Fernandez-Borrell J, Guerrero R. Rapid spectrofluorometric screening of poly-hydroxyalkanoate-producing bacteria from microbial mats. Int Microbiol. 2006; 9:95-102.

Chien CC, Chen CC, Choi MH, Kung SS, Wei YH. Production of poly-betahydroxybutyrate (PHB) by Vibrio spp. isolated from marine environment. $J$ Biotechnol. 2007; 132: 259-263.

Chowdhury AA. Poly- $\beta$-hydroxybuttersäure abbauende Bakterien und Exoenzyme. Arch Mikrobiol. 1963; 47: 167-200.

Findlay RH, White DC. Polymeric Betahydroxyalkanoates from environmental samples and Bacillus megaterium. Appl Environ Microbiol.1983; 45: 71-78.

Ghate B, Pandi P, Kulkarni C, Mungi DD, Patel TS. PHB Production using novel agro-industrial sources from different Bacillus Species. Int J of Pharm Biol Sci. 2011; 2:242-249.

Ha CS, Cho WJ. Miscibility, properties, and biodegradability of microbial polyester containing blend. Prog Polym Sci. 2002; 27: 759-809.

Hirad AH, Bahkali AH, Mohamed AK, Abdallah ME and Basheer AA. Antimicrobial Activity of Marine Microorganisms Isolated from the Coast of the Arabian Gulf. J pure ApplMicrobiol. 2013; 7: 11591164.

Khiyami MA, Sulaiman M, Al-Fadual, Ali HB. Polyhydroxyalkanoates production via Bacillus plastic composite support (PCS) biofilm and date palm syrup. J Med Plants Res. 2011; 5: 3312-3320.

Lee SY. Bacterial Polyhydroxyalkanoates. Biotechnol Bioeng.1996; 49: 1-14.

Macrae RM, Wilkinson JF. Poly- $\beta$-hyroxybutyrate Metabolism in Washed Suspensions of Bacillus cereus and Bacillus megaterium. J Gen Microbiol. 1958; 19: 210-222.
Mahmoud M, Berekaa, Ali M, Al Thawadi. Biosynthesis of polyhydroxybutyrate (PHB) biopolymer by Bacillus megaterium SW1-2: Application of Box-Behnkenesign for optimization of process parameters. Afr J Microbiol Res. 2012; 6: 838-845

Mergaert J, Swings J. Biodiversity of microorganisms that degrade bacterial and synthetic polyesters. $J$ Ind Microbiol Biotechnol. 1996; 17: 463-469.

Ostle AG, Holt JG. Nile blue A as a fluorescent stain for poly-hydroxybutyrate. Appl Environ Microbiol. 1982; 44: 238-241.

Pal A, Prabhu A, Kumar AA, Rajagopal B, Dadhe K, Ponnamma V, et al. Optimization of process parameters for maximum poly (- $\beta$-)hydroxybutyrate (PHB) production by Bacillus thuringiensis IAM 12077. Pol J Microbiol. 2009; 58: 149-154.

Ramchander M, Girisham S, Reddy SM. Production of phb (polyhydroxybutyrate) by Rhodopseudomonas palustris KU003 and Rhodobacter capsulatus KU002 under phosphate limitation. Int J Appl Biol Pharm. 2010; 1: 847-950.

Reddy CSK, Ghai R, Rashmi, Kalia VC. Polyhydroxyalkanoates: an overview. Bioresource Technol.2003; 87:137-146.

Redzwan G, Gan S, Tan IKP. Short Communication: Isolation of polyhydroxyalkanoate-producing bacteria from an integrated-farming pond and palm-oil mill effluent ponds. World J Microb Biot. 1997; 13:707709.

Rohini D, Phadnis S, Rawal SK. Synthesis and characterization of poly- $\beta$ - hydroxybutyrate from Bacillus thuringiensis R1. Indian J Biotechnol. 2006; 5: 276-283.

Singh M, Kumar P, Patel SKS, Kalia VC. Production of Polyhydroxyalkanoate Co-polymer by Bacillus thuringiensis. Indian J Microbiol. 2013; 53:77-83.

Sun W, Cao JG, Teng K, Meighen EA. Biosynthesis of poly-3-hydroxybutyrate in the luminescent bacterium, Vibrio harveyi, and regulation by the lux autoinducer $N$-(3-hydroxybutanoyl) homoserine lactone. J Biol Chem.1994; 269: 20785-20790.

Verlinden RA, Hill DJ, Kenward MA, William CD, Radecka 1. Bacterial synthesis of biodegradable polyhydroxyalkanoates. J Appl Microbiol. 2007; 102: 1437-1449.

Witholt B, Kessler B. Perspectives of medium-chain length poly (hydroxyalkanotes), a versatile set of bacterial bioplastics. Curr Opin Biotechnol. 2002; 10:279-285. 